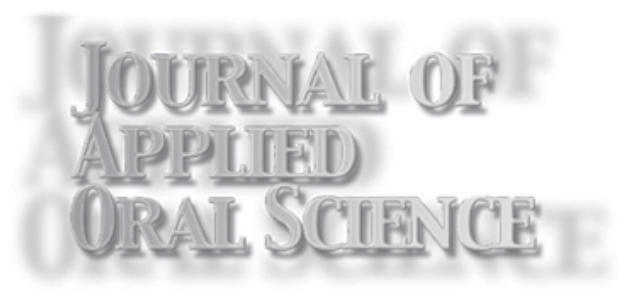

ISSN 1678-7757

\title{
Editorial
}

\section{Antibiotic prophylaxis guidelines for infective endocarditis}

Since infective endocarditis (IE) is a life-threatening infection, dentists should be aware of antibiotic prophylaxis guidelines.

The American Heart Association (AHA) ${ }^{4}$ and the British Society for Antimicrobial Chemotherapy $(B S A C)^{2}$ have currently updated their recommendations. In general, both guidelines reflect the need to avoid the overuse of antibiotics, which may lead to the development of bacterial resistance. Providers must choose the most recent guidelines from recognized authorities. Regardless of the guideline employed, it is instrumental that the most recent version is followed ${ }^{3}$.

The most important aspect for the prevention of IE is to classify both the patient and the procedure at risk (i.e., bleeding risk, bacteremia risk and subject risk) ${ }^{3}$. Practioners tend to employ antibiotics prophylaxis according to the guidelines in place at the time of their graduation from dental school ${ }^{1}$, therefore this approach may not be updated ${ }^{3}$.

The AHA recently concluded that only an extremely small number of cases of IE might be prevented by antibiotic prophylaxis for dental procedures. Therefore, dentists are more than invited to read the current recommendations ${ }^{2,4}$ in order to make a decision of which updated guideline should be followed.

Carlos F. Santos, DDS, PhD, Associate Professor Editor-in-Chief Journal of Applied Oral Science
1 - Epstein JB, Chong S, Le ND. A survey of antibiotic use in dentistry. J Am Dent Assoc. 2000;131:1600-9.

2 - Gould FK, Elliott TS, Foweraker J, Fulford M, Perry JD, Roberts GJ, et al. Guidelines for the prevention of endocarditis: report of the Working Party of the British Society for Antimicrobial Chemotherapy. J Antimicrob Chemother. 2006;57:1035-42.

3 - Sroussi HY, Prabhu AR, Epstein JB. Which antibiotic prophylaxis guidelines for infective endocarditis should Canadian dentists follow? J Can Dent Assoc. 2007;73:401-5.

4 - Wilson W, Taubert KA, Gewitz M, Lockhart PB, Baddour LM, Levison M, et al. Prevention of infective endocarditis: guidelines from the American Heart Association: a guideline from the American Heart Association Rheumatic Fever, Endocarditis and Kawasaki Disease Committee, Council on Cardiovascular Disease in the Young, and the Council on Clinical Cardiology, Council on Cardiovascular Surgery and Anesthesia, and the Quality of Care and Outcomes Research Interdisciplinary Working Group. J Am Dent Assoc. 2007;138:739-45, 747-60. 